\title{
Evaluation of the Relationship Between Oral Diseases and Glycemic Control in Insulin Dependent Diabetic (IDD) Children Cared in Health Center of Dakar / Senegal
}

\author{
Aida Kanouté, Mbathio Diop, Boubacar Samba Dankoko, Cheikh Mouhamadou Mbacké Lo, \\ Daouda Faye
}

Department of Public Health, Faculty of Medicine, University Cheikh Anta Diop of Dakar, Dakar, Senegal

Email address:

aida.kanoute@gmail (A. Kanouté)

\section{To cite this article:}

Aida Kanouté, Mbathio Diop, Boubacar Samba Dankoko, Cheikh Mouhamadou Mbacké Lo, Daouda Faye. Evaluation of the Relationship Between Oral Diseases and Glycemic Control in Insulin Dependent Diabetic (IDD) Children Cared in Health Center of Dakar / Senegal. Science Journal of Public Health. Vol. 5, No. 6, 2017, pp. 440-445. doi: 10.11648/j.sjph.20170506.15

Received: September 13, 2017; Accepted: October 8, 2017; Published: November 8, 2017

\begin{abstract}
Oral diseases are among the foremost complications observed due to diabetes. Diabetic patients are more likely to develop serious gum diseases which contribute to the worsening of diabetes by causing a disruption of blood glucose. The study aims to investigate the relationship between oral disease and IDD in children in the Marc SANKALE health center of Dakar. The oral examination was based on oral hygiene and caries status. The main results obtained contain the following: unbalanced supply for $17.9 \%$ cases, good glycemic control was observed in $19.6 \%$ of the cases, irregular brushing was reported in $76.8 \%$ of the total cases under consideration, the average moderate gingival inflammation and oral hygiene was observed in $80.4 \%$ cases. Glycemic balance influenced by some other factors such as: age, gender, parental occupation, education level, job insecurity, additional health coverage, care seeking and tooth brushing (OR $>1)$. An awareness of the importance of good oral hygiene will contribute to the diabetic balanced control or to treat diabetes.
\end{abstract}

Keywords: Dental Disease, Children, Insulin Dependent Diabetes, Dakar

\section{Introduction}

The dentist, during his professional activity, is expected to meet with general diseases that may interfere with his actions and requirements. The dentist must know these conditions to participate in multidisciplinary care [1]. Among these conditions we have the diabetes mellitus which is defined as a chronic endocrine disorder characterized by the presence of hyperglycemia due to a relative or absolute insulin deficiency [2]. It is also defined as a chronic hyperglycemia due to absolute or relative insulin insufficiency occurred from genetic and / or environmental factors.

There are two main types of diabetes: type 1 (insulin dependent) and type 2 (non-insulin dependent). Type 1 is often found in children. It is defined as a progressive achievement of insulin-secreting B cells of the pancreas resulting in absolute insulin deficiency. It is divided into two subtypes: autoimmune and idiopathic. This type of diabetes accounts for about $10 \%$ of all of the diabetic population. It occurs at any age, especially before 20 years old.

The severity of the disease lies on short or long-term complications which are: discomfort and hypoglycemic coma, ketoacidosis, micro angioplasty (retinopathy, nephropathy, and neuropathy). In this situation, types of oral complications are: xerostomia, cheilitis angular, glossitis median rhomboid, abundant tartar, edematous mucosa, relatively frequent caries and periodontal disease including type of gingivitis and periodontitis. These pathologies of infection from them may make the diabetes balance difficult. The latter can also maintain or cause mouth infection. According to BIHAN H. et al., patients with diabetes are not only more likely to develop serious gum disease, but it is also noted that these contribute to the worsening of diabetes by causing a disruption of blood sugar level [3].

For example, a number of studies have been carried out in the prevention of caries by means of health coaching on the self-efficacy of the toothbrush (TBSE) and the frequency of toothbrushing (TB) and their effects on the management of the 
diabetes. Despite all these efforts, the problems persist $[4,5]$.

To pour an effort to improve care for diabetic children, the objective of this study was to analyze the relationship between oral disease and glycemic control in insulindependent children receiving treatment in the Marc SANKALE health center of Dakar. The specific objectives of this study are to identify oral diseases observed in children with diabetes, to analyze the relationship between diabetes and types of oral lesions and to determinate factors that can disrupt blood sugar control.

\section{Materials and Methods}

\subsection{Study Type}

This was a descriptive and analytical cross-sectional study of insulin-dependent children.

\subsection{Population and Duration Study}

The study was done for the frame center Marc SANKALE of Abass NDAO Hospital of Dakar, which is the only specialized structure in the management of diabetes in Senegal.

The study lasted for one year, from September 2013 to September 2014 and covered all insulin-dependent children found in the center during that period.

\subsubsection{Eligibility Criteria for Subjects'Selection Criteria}

a. Inclusion criteria

The inclusion criteria being followed in this study were as follows: Any diabetic child aged from 6 to 15 years with type 1 diabetes who is being followed up in the Marc SANKALE center of Abass NDAO Hospital; irrespective of the duration of his diabetes and glycemic equilibrium. Only details of those children were included in the study whose parents consent was obtained.

b. Exclusion criteria

Those patients and parents refused to participate in the study were excluded.

\subsubsection{Materials Used for the Oral Examination}

The questioning, observation and clinical measurements were performed by a dentist and the equipment used for each patient consist of a review board with a mirror, a periodontal probe, tweezers, probes 6 and 17, rolls of cotton, sterile compresses, gloves and masks.

The information and data collected by the examiner were recorded in a survey sheet.

\subsubsection{Elements of the Survey Sheet}

The survey sheet contained the following information:

The general information of the sheet contained the data regarding health examination, identification of the patient (Vital), frequency of brushing after every meal, occupations of parents having the following details: employed, unemployed, pensioners, farmers / household, academic background status of parents: none, primary, secondary, other, socioeconomic Edge: measured by the poverty line is $\$ 1.25$ a day, complementary health coverage status: complementary private health, universal health coverage, care over the last 24 months: reporting a dental visit in the past two years.

Diabetes associated information were also collected. It was carried out by a physician and diabetes specialist doctor and focused on the following criteria: span of diabetes (whether patient is having diabetes less than 5 years or more), current ongoing treatment (whether patient in on insulin or not), present Glycemic Balance of the patient $(0.80 \mathrm{~g} / 1 \leq$ glycémie $\leq 1,26 \mathrm{~g} / \mathrm{l})$, history of acute complications of the patient, presence or absence of any associated pathologies.

Details of the oral examination of each considered patient were another vital criterion of the study. For the oral examination, we identified the following parameters: oral hygiene, decayed teeth, gingival inflammation and condition of surrounding mucosa. Assessing the level of hygiene was made by plaque index (PLI) LOE and SILNESS: it determines the quality of oral hygiene by quantifying the deposits on the tooth surfaces.

The scoring system considered is as follows:

Score $0=$ no plaque;

Score $1=$ plaque detected with a probe by scraping the tooth surface in contact with the marginal gingival;

Score 2 = plaque visible to the naked eye in moderation;

Score $3=$ tooth surfaces covered with a large plate quantity.

The interpretation of the index was made according to the recommendations of Martin and Bercy that can qualify plaque control (effective oral hygiene) as the value of fold intervals:

$0=$ excellent,

0.1 to $0.6=$ good,

0.7 to $1.9=$ average,

2 to $3=$ low.

The evaluation of the gingival condition was performed by gingival index (GI). The scoring system considered is as follows:

Score $0=$ no visible inflammation;

Score 1 = mild inflammation without bleeding on probing;

Score 2 = moderate inflammation with bleeding caused;

Score 3 = severe inflammation with ulceration and spontaneous bleeding.

The interpretation of the index was made as recommended by MARTIN and BERCY that can quantify gingival inflammation according to the ranges of values that are identical to those of the plaque index. It was thus: absence of inflammation, mild inflammation, moderate inflammation and severe inflammation. The evaluation of dental status was performed by caries index (DMF/tooth), which measures the ratio of decayed teeth by reporting to healthy teeth. The average index also was calculated.

\subsection{Statistical Analysis of Data}

Data were analyzed by Epi info version 6.04 and Excel. The Comparison of qualitative variables was performed using chi-square while the Anova test was used to compare quantitative variables. The significance level considered was $\mathrm{p}<0.05$. Logistic regression was performed to quantify the relationship between glycemic control (average glucose 
control or bad) with the main variables studied.

$\mathrm{OR}=1$ : the glycemic control is independent of the variable;

OR > 1: glycemic imbalance is more common for people who have the characteristic;

$\mathrm{OR}<1$ : glycemic imbalance is more common in individuals who do not have the feature.

\section{Results}

\subsection{Descriptive Results}

\subsubsection{Socio-Demographic Characteristics of the Study Population}

Table 1. Probability of an imbalance blood glucose control during the past 2 years.

\begin{tabular}{|c|c|c|c|}
\hline & $\begin{array}{l}\text { Frequency } \\
\text { (n) }\end{array}$ & $\begin{array}{l}\text { Percentage } \\
(\%)\end{array}$ & $\begin{array}{l}\text { Logistic } \\
\text { model (OR) }\end{array}$ \\
\hline \multicolumn{4}{|l|}{ Age } \\
\hline 6 to 9 & 24 & 14.3 & 1.367 \\
\hline 10 to 12 & 66 & 39.3 & 1.112 \\
\hline 13 to 15 & 78 & 46.4 & 1 \\
\hline \multicolumn{4}{|l|}{ Gender } \\
\hline Male & 54 & 32.1 & 0.643 \\
\hline Female & 114 & 67.9 & 1.1 \\
\hline \multicolumn{4}{|l|}{ Occupation of parents } \\
\hline Employed & 18 & 10.7 & 1 \\
\hline Unemployed & 30 & 17.8 & 1.342 \\
\hline Retired & 39 & 23.2 & 1.231 \\
\hline Peasants, housewives & 81 & 48.3 & 1.575 \\
\hline \multicolumn{4}{|l|}{ Study level } \\
\hline Not scholarized & 21 & 12.5 & 1.653 \\
\hline Primary & 99 & 58.9 & 1.356 \\
\hline Secondary and more & 48 & 28.6 & 1 \\
\hline \multicolumn{4}{|l|}{ Insecurity } \\
\hline No precarious & 30 & 17.9 & 1 \\
\hline Precarious & 138 & 82.1 & 1.562 \\
\hline \multicolumn{4}{|l|}{ Complementary cover } \\
\hline Additional private health & 24 & 14.3 & 0.631 \\
\hline Universal Health Coverage & 12 & 7.1 & 0.526 \\
\hline $\begin{array}{l}\text { No additional health } \\
\text { coverage }\end{array}$ & 132 & 78.6 & 1.631 \\
\hline \multicolumn{4}{|c|}{ Use of oral care during the last 24 months } \\
\hline Oral care & 45 & 26.7 & 1 \\
\hline No oral care & 123 & 73.3 & 1.362 \\
\hline \multicolumn{4}{|c|}{ Tooth brushing after each meal } \\
\hline Teeth brushing & 39 & 23.2 & 1 \\
\hline No teeth brushing & 129 & 76.8 & 1.27 \\
\hline TOTAL & 168 & 100 & \\
\hline
\end{tabular}

168 children in the sample were aged between 6 and 15 years, the average age was $12.16 \pm 2.4$ years.

\subsubsection{Diabetes Features}

The observations found in this study are described in the following section. The mean duration of diabetes was $2.55 \pm$ 0.37 years. In the study population, $82.1 \%$ of patients had a balanced diet in contrast to $17.9 \%$ not having so. A little less than half of the study population $(46.4 \%)$ had poor glycemic control (blood glucose $\geq 1.4 \mathrm{~g} / \mathrm{l}$ ), $33.9 \%$ had an average glycemic control $(1.26 \mathrm{~g} / \mathrm{l}<$ glucose $<1.4 \mathrm{~g} / \mathrm{l})$ and $19.6 \%$ with a good glycemic control $(0.80 \mathrm{~g} / \mathrm{l} \leq$ glycémie $\leq 1,26 \mathrm{~g} / \mathrm{l})$. The acute complications covered $55.4 \%$ of the study population and most of the cases are hypoglycemic attacks. Chronic complications were encountered only in $5.4 \%$ of cases. Assessment of the duration of diabetes showed that $84 \%$ of the study populations were living with diabetes for a maximum of 5 years and $16 \%$ for more than 5 years. It was found that over $2 / 3$ of our patients had at least one diabetic parent. We detected pathologies associated with diabetes in $20 \%$ of cases. The most frequent were: asthma, sickle cell disease, sinusitis, heart disease, trisomy 21 and otitis.

\subsubsection{Oral Aspects}

a. Tooth brushing

More than 3/4 of children (76.8\%) do not brush their teeth regularly (after each meal).

b. Periodontal Health Index

A significant proportion of the study population $(80.4 \%)$ had moderate gingival inflammation and an average oral hygiene.

c. Caries index

More than half of patients $(57.2 \%)$ had a caries index between 0.01 and 0.4 .

\subsection{Analytical Results}

\subsubsection{Glycemic Balance and Gingival Inflammation}

Table 2. Distribution (\%) of diabetics based on glycemic control as gingival inflammation.

\begin{tabular}{llll}
\hline & \multicolumn{2}{l}{ Gingival inflammation } \\
\hline Glycemic control & $\begin{array}{l}\text { Mild } \\
\text { inflammation } \\
(\%)\end{array}$ & $\begin{array}{l}\text { Average } \\
\text { inflammation } \\
(\%)\end{array}$ & $\begin{array}{l}\text { Severe } \\
\text { inflammation } \\
(\%)\end{array}$ \\
\hline Good & 75.0 & 13.3 & 28.6 \\
Average & 25.0 & 40.0 & 0.0 \\
Bad & 0.0 & 46.7 & 71.4 \\
Chi-square: 3.2 & p: 0.010 & & \\
\hline
\end{tabular}

\subsubsection{Evolution of Diabetes Duration, Gingival Inflammation and Caries Index}

Table 3. Distribution (\%) of diabetics based on duration diabetic evolution according to gingival inflammation.

\begin{tabular}{llll}
\hline & \multicolumn{3}{l}{ Evolution of the duration of diabetes } \\
\hline $\begin{array}{l}\text { Inflammation } \\
\text { gingival }\end{array}$ & $\begin{array}{l}\text { 0 to } 5 \\
\text { years(\%) }\end{array}$ & $\begin{array}{l}\text { 6 years } \boldsymbol{\&} \\
\text { over(\%) }\end{array}$ & Global(\%) \\
\hline Mild inflammation & 8.5 & 0.0 & 7.1 \\
Average Inflammation & 78.7 & 88.9 & 80.4 \\
Severe Inflammation & 12.8 & 11.1 & 12.5 \\
Chi-square: 0.880 & p: 0.644 & & \\
\hline
\end{tabular}

Table 4. Distribution (\%) of diabetics based on duration diabetic evolution according to caries index.

\begin{tabular}{llll}
\hline \multicolumn{4}{l}{ Evolution duration of diabetes } \\
\hline Caries index & 0 to 5ans(\%) & $\begin{array}{l}\text { 6 years \& } \\
\text { Over(\%) }\end{array}$ & Global(\%) \\
\hline 0 & 46.8 & 22.2 & 42.9 \\
0.01 to 0.09 & 29.8 & 22.2 & 28.6 \\
0.1 to 0.4 & 23.4 & 55.6 & 28.6 \\
Chi-square: 3.950 & p: 0.139 & & \\
\hline
\end{tabular}




\subsubsection{Glycemic Balance and Caries Index}

Table 5. Distribution (\%) of diabetics based on caries index according to glycemic equilibrium.

\begin{tabular}{|c|c|c|c|c|}
\hline \multicolumn{4}{|c|}{ Caries Index } & \multirow{2}{*}{$\begin{array}{l}\text { Global } \\
(\%)\end{array}$} \\
\hline $\begin{array}{l}\text { Glycemic } \\
\text { equilibrium }\end{array}$ & $0(\%)$ & $\begin{array}{l}0.01 \text { to } \\
0.09(\%)\end{array}$ & $\begin{array}{l}0.1 \text { to } \\
0.4(\%)\end{array}$ & \\
\hline Good & 16.7 & 31.3 & 12.5 & 19.6 \\
\hline Average & 33.3 & 43.8 & 25.0 & 33.9 \\
\hline Bad & 50.0 & 25.0 & 62.5 & 46.4 \\
\hline Chi-square: 4.993 & p: 0.29 & & & \\
\hline
\end{tabular}

\section{Discussion}

\subsection{Constraints and Limitations of the Study}

This study lasted one year during which insulin-dependent children who came for consultation in the Marc SANKALE center, have been selected after receiving their parents' consent. The proposed dental consultations were an additional problem for children, such as lack of motivation, their schooling constraints and fear. However, we did have the support of the Senegalese Association of Diabetic Support (SADS).

\subsection{Socio-Demographic Characteristics of the Study Population}

The sample consists of 168 diabetic patients aged 6 to 15 years that we consulted in the Marc SANKALE center of Abass NDAO hospital in Dakar from September 2013 to September 2014. The average age was $12.16 \pm 2.4$ years, and almost half were aged between 13 and 15 years. Thiam found an average of $11.10 \pm 0.40$ years in a 6 to 15 -year range [6]. Siudikiene et al. found an average age of 13.6 on the 10 to 15 range [7]. Twetman et al. in their forward-looking work carried out on 80 Type 1 diabetes patients found an average age of 14,5 years on an age interval from 11.7 to 18.4 years [8]. The study showed a female predominance over the male, similar to the earlier report of Lecor and Diatta $[9,10]$. Thiam and Twetman have found conflicting results; indeed there were more boys than girls $[6,8]$. Moore et al. reported the equivalent number of boys and girls [11]. It is strongly dominated by the informal sector (Table 1). The study showed that $87.5 \%$ of parents were schooled among whom more than $2 / 3$ had preliminary education up to the elementary school (Table 1). Parental education level plays an important role in the care management of children. Indeed, the inclusion of children whose parents had a high school level education was generally having a better situation than others [11].

Balanced Food: The study showed that among the 168 patients consulted, 138 had followed a balanced diet, even though most of them were living in Dakar suburb where poverty is dominant in general. Thiam found in his study that the majority of diabetics did not have an adequate diet [6]. The proper diet is essential in diabetes control. However, it is difficult to enforce on all, especially, in a context of poverty where ample resources are required.

\subsection{Glycemic Balance}

Despite the fact that the majority has been monitoring their diet regularly, blood sugar control was good for only $19.6 \%$ cases, slightly lower than the results of Thiam, who found $25 \%$ of the total cases. The high frequency of patients with unbalanced blood sugar can be promoted by the weariness of the patients in front of a chronic condition, by the inconstancy in the regular monitoring of treatment or by the financial difficulties and the high cost of drugs [6]. In addition to this, children and their parents, often from disadvantaged backgrounds, are not made aware of the importance of a diet or its continuous monitoring.

\subsection{Glycemic Balance and Gingival Inflammation}

Our study showed that blood sugar control can also be influenced by other factors such as age, gender, parental occupation, level of education, job insecurity, the additional health coverage, the use of care and regular tooth brushing (Table 2). The glycemic control, according to age and gender: it is more common in youngster $(\mathrm{OR}=1.367)$ and females (1.1). Children whose parents are unemployed, pensioners, farmers or housewives, have a high frequency of glycemic control $(\mathrm{OR}>1)$. It is the same for children whose parents have at most a primary level of study. Precariousness also plays a negative role in glycemic control $(\mathrm{OR}=1.562)$. The latter is also disturbed by the absence of additional coverage $(\mathrm{OR}=1.631)$ and also by the lack of care seeking during the past two years $(\mathrm{OR}=1.362)$. The lack or absence of regularity in the tooth brushing is related to the glycemic control $(\mathrm{OR}=1.27)$. Indeed, the absence of regular tooth brushing is often the cause of gingivitis that might disrupt glycemic control [7]. The accumulation of medical and social vulnerabilities in this case, be it diabetic child of poor parents, uneducated or at a low socioeconomic level, with no medical coverage, with no recourse to care for two years and an irregular dental brushing, further reduces the likelihood of having glycemic equilibrium.

Complications: acute complications are more often encountered $(55.4 \%)$ and chronic complications were rare (5.4\%). Lecor found $55 \%$ of acute complications [9]. Chronic complications vary with balance and duration of diabetes.

Duration of diabetes: among the 168 patients, the average duration of diabetes was $2.55 \pm 0.37$ years; 141 patients had diabetes for more than 5 years and 27 of at least for 5 years. Thiam reported an average duration of diabetes of $3.5 \pm 0.45$ years, which is higher than the average found in this study [6]. Lecor found for 30 diabetic patients, out of which, 17 had a record of diabetes of 1 to 4 years and 13 with more than 5 years [9].

Family history: Diabetes was found in families of diabetic children in $67.9 \%$ of cases, Thiam informed of $50 \%$ in Senegalese families [6].

Associated pathologies: only $19.6 \%$ of our enlisted patients have pathology associated with diabetes. 


\subsection{Oral Aspects}

\subsubsection{Brushing}

The study showed that $76.8 \%$ of patients do not brush their teeth regularly. Thiam found that diabetic patients used the toothbrush in $85 \%$ of cases, but the frequency of brushing multiple times in a day was as low as $17.5 \%$ who brushed their teeth at least 2 times a day [6]. The irregular brushing percentage may be due to lack of motivation and an educational deficiency regarding oral hygiene of the patients.

\subsubsection{Periodontal Health Indices, Periodontal Disease Indices}

The overage plaque index was $1.3889 \pm 0.45$ in patients. The work of Tshongo et al. corroborates our results because the gingival bleeding during oral hygiene care is reported by one third of the patients, particularly type 1 diabetic [12]. Thiam has shown that this average was $1.46 \pm 0.08$ in diabetic patients [6].

Alves Shows that there is no difference between diabetic and non-diabetic patients in the found DMF-T/def-t indices $(\mathrm{P}=0.43 / 0.14)$. However, the visible plaque index (VPI) was similar in both groups $(\mathrm{P}=0.15)$. GBI $(\mathrm{VPI})$ and gingival bleeding index (GBI). The test was utilized when the variables showed normal was higher in the diabetics (8.1 vs. 5.18; $\mathrm{P}=0.11)$ [11].

Azogui-Lévy explains that high frequency of gingivitis may occur due to various reasons [14], such as, increased formation of dental plaque and tartar in connection with the same salivary changes to the genesis of dental caries, the susceptibility of the diabetic patient to infection by inhibiting the function of macrophages and neutrophils, inducing bacterial proliferation aggravated by the presence of plaque itself instead of bacterial proliferation and the presence of micro angioplasty in the gingiva of the diabetic.

The results also showed that gingival inflammation increased with glycemic control (Table 2). The observations suggest that worsen the glycemic control is, severe was the gingival inflammation. Gingival inflammation participates in the imbalance of diabetes. Hyperglycemia promotes the growth of bacteria in dental plaque, but also induced an inflammatory response and destruction of connective tissue promoting periodontitis. Simultaneously, chronic inflammation induced by periodontal disease contributes to insulin resistance mechanism and therefore to hyperglycemia. It is, therefore, important in the prevention and treatment of diabetes to take account of oral hygiene. The diabetes management should be in a multidisciplinary context where the dental staff has an important role to play. The Abass Ndao hospital that houses the center Marc Sankalé, provided with a dental service to improve the effectiveness and efficiency in the management of diabetes in general.

\subsubsection{Evolution of Diabetes Duration, Gingival Inflammation and Caries Index}

Furthermore, this study has yet not found a relationship between duration of diabetes and gingival inflammation (Table 3). Other authors who have conducted similar studies on adults with diabetes patients have shown a relationship between the degree of evolution of diabetes and gingival inflammation. Thiam's study showed that gingivitis increases with duration of diabetes and glycemic control [6]. According to Bissonget al., there is a greater prevalence of severe gingivitis, periodontitis, especially in diabetic subjects than in non-diabetics. Thirty five out of 149 (23.5\%) diabetic patients had gingivitis; 37 (24.8\%) had periodontitis; 29 $(19.5 \%)$ had dental caries and $32(21.5 \%)$ had oral candidiasis. Gingivitis, periodontitis and oral candidiasis were significantly higher in diabetics than non-diabetics [15]. Other authors have also shown that periodontal disease has a greater correlation with age of the child rather than the duration of the disease, unlike that we can see in adults [16, 17]. There is a mutual relationship between severe oral disease and the development of diabetes. All studies showed higher prevalence of xerostomia in diabetes patients in relation to non-diabetic population, $12.5 \%-53.5 \%$ versus 0 $30 \%$ [16]. The reduction of saliva predisposes to enamel hypomineralization and caries formation [19].

However, there is conflicting evidence in the caries experience between children with type 1 diabetes and healthy children. For periodontal health, most studies significantly reported greater plaque accumulation and higher gingival index in children with type 1 diabetes. Cohort studies reported no significant differences in periodontal parameters over time. [20].

Patients with diabetes are not only more likely to develop serious gum disease, but it is also noted that this will contribute to the worsening of diabetes by causing a disruption of blood glucose [21]. Diabetics are at risk to develop more gum disease because not only they are at higher risk of bacterial infection, but they also have a lower metabolism to fight oral infections [22].

\subsubsection{Glycemic Balance and Caries Index}

Our study also showed the absence of relationship between dental caries and degree of development of diabetes in insulin-dependent children (Table 4). It is the same between tooth decay and glycemic control (Table 5). In adults, Siudikiene showed that diabetic patients were more likely to develop tooth decay, showing that caries increased with disease duration of diabetes and glycemic control [7].

\section{Conclusion}

The fact of being a diabetic child from poor backgrounds, unschooled or from a low socioeconomic level, not having any medical coverage, with no recourse to care for two years, with an irregular tooth brushing, further reduces the likelihood of having a balanced blood sugar level. An awareness of the importance of maintaining good oral hygiene among insulin dependent children, recourse to regular care through supplementary health coverage, will contribute to diabetic equilibrium control or to the treatment of the diabetes. It is important to create an oral health service in diabetic care centers. One of the WHO's recommendations, 
through the resolution of WHA 60-17 in 2007 follows an integrated approach in this direction.

\section{References}

[1] Otomo-Corgel J, Pucher JJ, Rethman MP, Reynolds MA. State of the science: chronic Periodontitis And Systemic Health. J Evid Based Dent Pract. 2012;12(3):20-28.

[2] Golden SH, Sapir T. Methods for insulin delivery and glucose monitoring in diabetes: summary of a comparative effectiveness review. J Manag Care Pharm. 2012;18(6):S1-17.

[3] Bihan H, Laurent S, Sass C et al. Association among individual deprivation, glycemic control and diabetes complications. The epices score. Diabetes care. 2005;28:26802685 .

[4] Cinar AB, Schou L. Impact of empowerment on toothbrushing and diabetes management. Oral Health Prev Dent. 2014;12(4):337-44. doi: 10.3290/j.ohpd.a32130.

[5] Cinar AB, Oktay I, Schou L. Self-efficacy perspective on oral health behaviour and diabetes management. Oral Health Prev Dent. 2012;10(4):379-87.

[6] Thiam M. Contribution à l'étude de l'état bucco-dentaire des enfants diabétiques. Thèse Chir. Dent. 2005, Dakar; n 24:104.

[7] Siudikiene J, Maciulskiene V, Nyvad B, Tenovuo J, Nedzelskiene. Dental Caries Increments and Related Factors in Children with Type 1 Diabetes Mellitus. Caries Res 2008;42:354-362.

[8] Twetman S, Petersson GH, Bratthall D. Caries risk assessment as a predictor of metabolic control in young Type 1 diabetics. Diabet Med. 2005 Mar;22(3):312-315.

[9] Lecor P A. Prise en charge des parodontopathies, facteurs d'équilibre du diabète sucré: (étude prospective cas témoins à propos de 90 malades au centre Marc SANKALE de Dakar Sénégal). Thèse Chir. Dent. 2000, Dakar; ${ }^{\circ}{ }^{\circ}$.

[10] Diatta M. Prévalence de la xérostomie chez le patient diabétique: A propos d'une étude prospective réalisée au centre Marc Sankalé. Thèse Chir. Dent. 2004, Dakar; $n^{\circ} 17$.

[11] Moore P A, Guggenheinmer J, Etzel K R, Weyant R J, Orchard T. Type 1 diabetes mellitus: xerostomia and salivary flow rates. Oral-surg, Oral-Med, Oral-path. 2001;92(3):281291.
[12] Tshongo M C, Preumont V, Reychler H, Rahelic D, Buysschaert M. Evaluation de l'hygiène buccodentaire dans une cohorte de patients diabétiques. Résultats d'une étude préliminaire chez 100 sujets diabétiques de type 1 et 2 . Louvain med 2015; 134 (9): 493-497.

[13] Alves C, Menezes R, Brandão M. Salivary flow and dental caries in Brazilian youth with type 1 diabetes mellitus. Indian J Dent Res. 2012;23(6):758-762.

[14] Azogui-Lévy S., Anagnostou F., Etienne D. « Santé buccodentaire et diabète ». Chapitre dans Traité de diabétologie sous la direction de A. Grimaldi ; Flammarion(2009).

[15] Bissong M, Azodo CC, Agbor MA, Nkuo-Akenji T, Fon PN. Oral health status of diabetes mellitus patients in Southwest Cameroon. Odontostomatol Trop. 2015 Jun;38(150):49-57.

[16] Pranckeviciene A, Siudikiene J, Ostrauskas R, Machiulskiene V. Severity of periodontal disease in adult patients with diabetes mellitus in relation to the type of diabetes. Biomed Pap Med Fac Univ Palacky Olomouc Czech Repub. 2014;158(1):117-123.

[17] Meenawat A, Punn K, Srivastava V, Meenawat AS, Dolas RS, Govila V. Periodontal disease and type I diabetes mellitus: Associations with glycemic control and complications. J Indian Soc Periodontol. 2013;17(5):597-600.

[18] López-Pintor RM, Casañas E, Serrano JG, Serrano J, Ramirez L, De ArribaL, Hernandez G. Xerostomia, Hyposalivation, and Salivary Flow in Diabetes Patients. J Diabetes Res.2016 (2016):1-15.

[19] Yeh CK, Harris SE, Mohan S, Horn D, Fajardo R, Chun YH, Jorgensen J, Macdougall $\mathrm{M}$, Abboud-Werner $\mathrm{S}$. Hyperglycemia and xerostomia are key determinants of tooth decay in type 1 diabetic mice. Lab Invest. 2012;92(6):868-882.

[20] Ismail AF, McGrath CP, Yiu CK. Oral health of children with type 1 diabetes mellitus: A systematic review. Diabetes Res Clin Pract. 2015;108(3):369-81.

[21] Kumar M, Mishra L, Mohanty R, Nayak R. Diabetes and gum disease: the diabolic duo. Diabetes Metab Syndr. 2014;8(4):255-258.

[22] Singh P N. Diabetes weds oral infection: An unhappy marriage. Am J Med Sci. 2013;5(5):337-8. 